\title{
Allograft Aortic Root Replacement for Aortic Valve Endocarditis with Aortopulmonary Fistula
}

\author{
Tanzer ÇALKAVUR, MD, Tahir YAĞDI, MD, Fatih ISLAMOǦLU, MD, \\ Yüksel ATAY, MD, Sanem NALBANTGiL, MD, and Mustafa ÖZBARAN, MD
}

\begin{abstract}
SUMMARY
Acute infective endocarditis affecting the aortic root and valve associated with development of a fistulous communication between the aorta and pulmonary artery was presented in a young Turkish girl. Emergency surgery was required. Operation consisted initially of closure of the defect on the main pulmonary artery with a pericardial patch. This was followed by allograft aortic root replacement. (Jpn Heart J 2001; 42: 261-264)
\end{abstract}

Key words: Endocarditis, Aortopulmonary fistula, Allograft

$\mathrm{IN}_{\mathrm{N}}$ spite of improvements in antibiotic treatment, infective endocarditis remains relatively common and a serious condition and surgery may be an essential therapeutic intervention, especially for congestive cardiac failure due to valvular lesions and intracardiac fistulas. Since the first successful prosthetic aortic valve replacement for infective endocarditis, mechanical valves, xenografts and allografts have been used effectively. ${ }^{1-3)}$ However, the incidences of reinfection, paravalvular leak and valve dehiscence are still high early after mechanical or xenograft valve replacement for infective endocarditis. Viable aortic allografts have been recommended for aortic valve replacement in infective endocarditis because of the low reinfection rate, free of thromboembolism and excellent durability. Aortopulmonary fistula associated with endocarditis complicating mechanical aortic valve replacement has been reported, ${ }^{4-6)}$ but to our knowledge there are no reports of aortopulmonary fistula following native aortic valve endocarditis in the English literature.

\section{CASE RePORT}

A 14-year-old Turkish girl with no known previous heart problem was hospitalized because of high fever, chills and fatigue. Coagulase positive Staphylo-

From Department of Cardiovascular Surgery, Ege University Medical Facultyq, Izmir, Turkey.

Address for correspondence: Mustafa Özbaran, MD, Ege Üniversitesi Tip Fakültesi, Kalp ve Damar Cerrahisi Anabilim Dal 35100 Izmir, Turkey.

Received for publication October 12, 2000.

Revised and accepted November 27, 2000. 


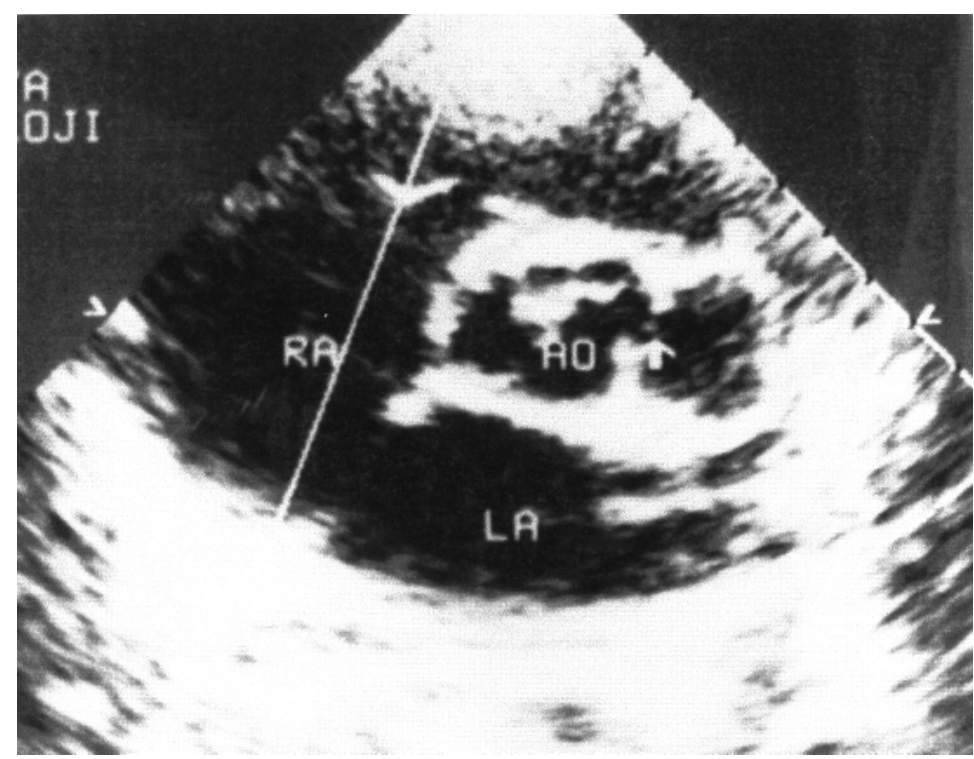

Figure 1. Preoperative transthoracic echocardiogram (white arrow showing aortapulmonary fistula).

coccus aureus was isolated from blood cultures. In spite of an appropriate antibiotic regimen, she remained pyrexial and 10 days later a diastolic heart murmur in the third left intercostal space developed associated with congestive heart failure, which required the administration of diuretics and inotropics. Echocardiogram showed severe aortic regurgitation, prolapse of the left coronary cusp of the aortic valve, aortopulmonary fistula and pericardial effusion (Figure 1). The patient was transferred to the operating room for an emergency operation because of sudden hemodynamic deterioration. The findings were free purulent pericardial fluid and abscess formation at the base of the ascending aorta. Before cardiopulmonary bypass, a marked continuous thrill was palpable in the root of the main pulmonary artery. Cardiopulmonary bypass was instituted using proximal ascending aorta and right atrial single venous cannula; the aorta was crossclamped and the myocardium was protected by cold blood antegrade and retrograde cardioplegia with intermittent cardioplegic reinfusion. Paraaortic abscess formation between the aortic root and main pulmonary artery was observed. The aorta was transected $1 \mathrm{~cm}$ above the sinotubular junction. The left coronary cusp of the aortic valve was detached from the aortic annulus. A fistulous connection approximately $5 \mathrm{~mm}$ in diameter was observed to connect the left coronary sinus to the root of the main pulmonary artery (Figure 2). Aortic valve and infected aortic wall tissues were excised as much as possible. Pulmonary arteriotomy was 


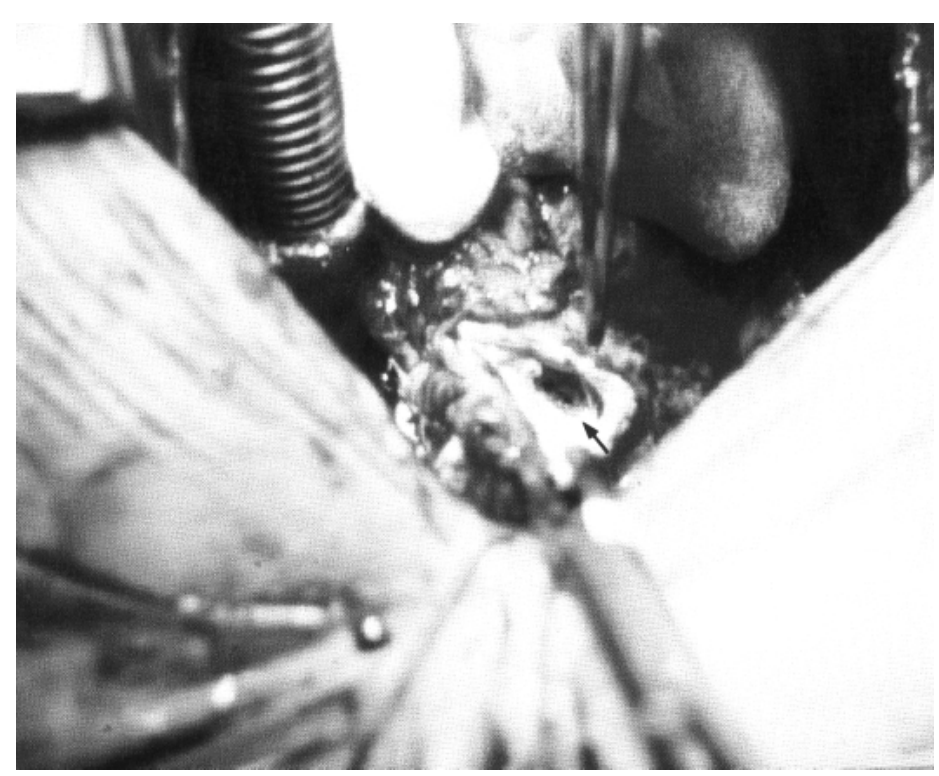

Figure 2. A fistulous connection between the left coronary sinus and the root of the main pulmonary artery (black arrow indicates a fistulous hole in the main pulmonary artery).

performed and a fistulous hole was seen in the main pulmonary artery. The defect on the main pulmonary artery was closed with a pericardial patch.

The diameter of the aortic root at the level of the annulus was measured using a prosthetic valve measuring device. A viable cryopreserved aortic valve allograft with an internal diameter of $19 \mathrm{~mm}$ was selected for aortic root replacement. The allograft was implanted in the anatomical position. The entire proximal suture line was placed below the annular level because of extensive tissue damage on the annulus of the left cusp. An interrupted 4-0 monofilament polypropylene suture was used proximal to the allograft suture line. Both the coronary ostial reimplantation and distal aortic anastomosis were performed with continuous 5-0 monofilament polypropylene suture. The patient required inotropic support during the early postoperative period. A culture of tissues debrided from the aortic cusps and wall confirmed coagulase positive Staphylococcus aureus and the initial appropriate antibiotic treatment was continued for the next 5 weeks. The postoperative period was uneventful and the patient was discharged 12 days after the operation. A postoperative echocardiogram before discharge showed normal function of the implanted allograft aortic valve and left ventricle. Three years after the operation, an echocardiographic evaluation was performed and no pathological findings were observed. 


\section{DisCUSSION}

Although congenital aortopulmonary fistulas are a well-known condition with congenital heart disease, acquired aortopulmonary fistulas are rare. The etiology of acquired aortopulmonary fistulas includes rupture of aortic aneurysms, trauma, aortic dissection and infective endocarditis with prosthetic aortic valve replacement. There are 3 reported cases in which aortopulmonary fistulas developed after aortic valve replacement with a mechanical valve due to infective endocarditis. ${ }^{4-6)}$ In the English literature, this is the first known case of an aortopulmonary fistula following native aortic valve endocarditis.

There is controversy concerning the optimal surgical method and type of valve in the presence of native valve endocarditis. When a mechanical valve and bioprosthesis are compared with an allograft valve, the risk of infection of an early allograft is lower in the early term after implantation, possibly due to the absence of a cloth sewing ring in the allograft valve. Another application was reported by Kitamura and coworkers who performed the Ross operation using a cryopreserved pulmonary homograft in 3 patients with healed infective endocarditis of the aortic valve. The follow-up results of the patients were satisfactory. ${ }^{7)}$

Aortic annular or aortic root involvement in endocarditis may complicate mechanical prosthesis or bioprosthesis valve replacement because of the rigid annular ring. The flexibility of an allograft valve may enable the surgeon to repair safely without traction to a fragile annulus. A viable aortic allograft, because of its resistance to early postoperative infection and its flexibility, is the first choice for aortic valve endocarditis.

\section{REFERENCES}

1. Lewis BS, Agathangelou NE, Colsen PR, Antunes M, Kinsley RH. Cardiac operation during active infective endocarditis. J Thorac Cardiovasc Surg 1982; 84: 579-84.

2. Sweeney MS, Reul GJ Jr, Cooley DA, et al. Comparison of bioprosthetic and mechanical valve replacement for active endocarditis. J Thorac Cardiovasc Surg 1985; 90: 676-80.

3. Wallace RB, Londe SP, Titus JL. Aortic valve replacement with preserved aortic valve homografts. J Thorac Cardiovasc Surg 1974; 67: 44-52.

4. Vieweg WV, Oury JH, Tretheway DG, Mattern AL. Aortopulmonary septal defect due to staphylococcal endocarditis. Chest 1974; 65: 101-3.

5. Thomas TV, Heilbrunn A. Prosthetic aortic valve replacement complicated by diphtheroid endocarditis and aortopulmonary fistula. Chest 1971; 59: 679-82

6. Aragam JR, Keroack MA, Kemper AJ. Doppler echocardiographic diagnosis of aortopulmonary fistula following aortic valve replacement for endocarditis. Am Heart J 1989; 117: 1392-4.

7. Kitamura S, Yagihara T, Niwaya K, et al. An experience with the Ross operation utilizing cryopreserved pulmonary homografts procured by and stored in our homograft valve bank. Kyobu Geka 2000; 53: 275-80. 